\title{
Adopting Digital Technology in Teaching and Learning Environment in Early Childhood Education Classes in Nairobi County, Kenya
}

\author{
Odundo Paul Amolloh ${ }^{1}$, Ganira Khavugwi Lilian ${ }^{1} \&$ Milimu Gladys Shaji ${ }^{2}$ \\ ${ }^{1}$ Department of Educational Communication and Technology, University of Nairobi, Kenya \\ ${ }^{2}$ Institute of Early Childhood, Faculty of Human Sciences, Macquarie University, Australia \\ Correspondence: Odundo Paul Amolloh, Department of Educational Communication and Technology, University \\ of Nairobi, P. O. Box 30197, Kenya.
}

Received: August 24, 2017

Accepted: September 20, 2017

Online Published: October 10, 2017

doi:10.20849/aes.v2i3.192

URL: https://doi.org/10.20849/aes.v2i3.192

\begin{abstract}
Dispositions towards use of digital technologies in modern early childhood settings have dramatically transformed aspects in education sector through development and integration of technology into education policy, curriculum and practice. Digital technology as a tool in instruction benefits learner's fine motor skills, language and communication readiness, mathematical thinking as well as positive attitudes towards learning. Conversely inadequate educational and digital competence hampers teachers in Early Childhood Education (ECE) access to digital technology. This study assessed ways in which teachers in ECE in Kenya access digital technologies. It was designed as a two-phase exploratory mixed methods study. The design allowed collection of data from two groups of ECE educators: case study and survey teachers. Case-studies of two ECE centers (low and high technology) involving $11 \mathrm{ECE}$ teachers were compared in order to examine similarities and differences in access to digital technologies. Similarly, teachers $(n=508)$ in two education zones were surveyed and drawn in terms of similarities and differences in access to digital technologies. Findings indicated that ECE teachers in Kenya have limited access to digital technologies due to non-availability in ECE teaching and learning environments. To address this challenge, the study recommends Ministry of education to put emphasis on funding technology resources in early childhood settings. Furthermore, teachers in ECE should be exposed to a variety of developmentally appropriate digital technologies in order to effectively enhance teaching and learning.
\end{abstract}

Keywords: early childhood education, digital technologies, access, learning environments

\section{Introduction}

Children in contemporary early childhood settings live in a world enveloped by technological innovation at home and in school causing challenges to parents, teachers, policy makers as well as curricular that meets needs of modern society. Saturation of digital technologies particularly computers has been found to improve social interaction. Cherney, \& Dempsey, (2010), found an increase in interaction when children worked in pairs at a computer than when playing with puzzles on the floor. When exposed to appropriate technologies, children become independent in learning and are more likely to grow into autonomous and successful technology users. In support of this contention, Yelland, (2010), opined that digital technology instruction aids learning predominantly mathematical skills, implying that sorting activities could be just as easy through use of computers as with use of concrete materials. In this regard, adequate access to technology may provide basic skills in which children acquire competency in order to be successful in school and develop skills critical for high order thinking.

Analysis by Zitter, \& Hoeve, (2011), illustrated that digital technologies make it possible for children to experience virtual tours and opportunities in viewing situations in real world which they might not have a chance of viewing. Hence, in instances where ECE teachers adopt appropriate technologies into pedagogical management, children experience increased motivation, improved collaboration and knowledge construction which in turn lead to enhanced class practices. However, despite continuing enthusiasms for technologies in modern world, teachers in ECE have limited access likely due to inadequate didactical curriculum competence. Additionally Fu, (2013), observed that inadequate access to digital technology in early childhood settings is due to a resistance within the field of wider community, who see the tool as neither appropriate nor important. In order to effectively guide instruction using digital technology, teachers in ECE need to reconceptualize pedagogy 
and learning opportunities for learners in the digital world to experience equal opportunities for learning.

Analysis by Australian Communications and Media Authority (2009) revealed that access to technology and internet is present in most households with children as in most kindergartens. This implies that rapid development in technology serves as an impetus for researchers in western world to examine practices related to children's access and experiences with digital technologies at home, relatives' places, friends' homes and in ECE settings. Evidence resulting from a suit of research studies by Plowman, McPake \& Stephen (2008: 2010); Plowman, Stevenson, Stephen, \& McPake (2012) affirmed that children as young as three to four years are able to access and use a broad range of digital technologies. Appropriate access allows children to learn use of digital technology as well as develop knowledge of the world from the nature of technologies in use. Plowman and et al., (2012) opined that the range of technologies accessed and used by children include; mobile phones, television with interactive features, technological toys, wide range of leisure technologies, such as television and DVD players, as well as video cameras and MP3 players; electronic musical instruments; iPods and CD players; hand-held devices; telephones; desktop, notebook computers; CD and cassette. Given the range of technologies accessed by children, there is need to develop knowledge about digital tools related to learners' cultural formation connected to content, methodologies, as well as values related to societal norms in order to achieve success in teaching and learning.

Additional studies by Nikolopoulou, Gialamas, and Batsouta (2010) in Greece showed that children in the age bracket of 4-6 access a wide range of technologies at home. The technologies include; television; toys-robots; DVD; music keyboard; CD/tape player and discs; handheld electronic games; game console; education software; digital camera; Microsoft office; computer; printer; video camera; and internet. While digital technology has high profile in ECE environments, teachers should ensure equity and access in order to address divide between preschool children who come with a wealth of experiences with technology and those who come from technology poor backgrounds.

According to Banas (2010), quality learning environments are critical in planning and implementation of digital technology in order to address gaps in teacher perception, confidence, training and conflicting professional views on whether technology acts as a tool in learning. To achieve this, ECE settings should increase learnerengagement with new technology through; supporting teachers' training in appropriate use of skills in digital technology, disseminating appropriate software to pre-schools as well as replacing traditional class settings with flexible learning centers accessible to digital technology. While there is considerable support for digital technology for enabling learning, it should be within quality pedagogical frameworks and access by pre-school teachers.

Further empirical evidence from Western nations indicated that children's experiences with digital technologies result in development of positive learning personalities including language enhancement, communication acquisition, and development of motor skill, (Nikolopoulou, 2014; Pohio, 2009; Rasanen, et al., (2009); Roberts-Holmes, 2013) social and motivation skills, (Roberts-Holmes, 2013) perseverance (Couse \& Chen, 2010) positive impact on cognitive development, (MaCarrick \& Li, 2007); emotional development, (Roberts-Holmes, 2013) numeracy skills, (Highfield \& Mulligan, 2007); creativity,(O'Hara, 2008) as well as independence (Voogt \& McKenney, 2008). Based on these observations, teachers in ECE need to recognize changing demographics by aligning pedagogy and curriculum to benefit children in the digital rich- world. This could be realized through including society's values, content standards, research findings, community expectations and culture into EEC curriculum. In addition, in order to enhance learning, digital technology should tap into learner's creativity to motivate curiosity, exploration, sharing, and problem solving skills.

Despite limited studies on ECE teachers' integration of technology in daily practice, the government of Kenya recognizes role of digital technologies in teaching and learning of pre-school children, Republic of Kenya (2012). Furthermore, the government supports use of technology in class focusing on; expanding, enriching, implementing, individualizing, differentiating and extending overall curriculum. Therefore, teachers in ECE require knowledge in technology, select appropriate software and websites, integrate technology into the curriculum and equip appropriate technology resources into classes. It is based on this background that the study examined adoption of digital technologies in early childhood teaching and learning environments in Nairobi County.

\section{Statement of the Problem}

Appropriate use of technology in early childhood settings reinforces learning, motivates learners and makes learning real. While proliferations of digital technology continue advancing globally, African countries experience a gap in its implementation. Analysis by Momanyi, Norby, \& Strand, (2006) in Kenya showed that 
computer use in classes is still in its early phases due to inadequacy of qualified teachers in ICT as well as poor perception by teachers. Though technology has become an ubiquitous element in modern society embracing many aspects of daily lives including social interactions, little is known about forms of digital technologies accessed and used by teachers in ECE in non-Western countries including Kenya. Given that future of integrating digital technology into class is growing rapidly, teachers should be equipped with skills and knowledge in developmentally appropriate technologies in order to enrich learning. It is in this regard that the study examined availability of digital technologies in ECE teaching and learning environments.

\section{Purpose and Objective}

The purpose of this study is to assess availability of digital technologies in ECE teaching and learning environments. The objective was to examine strategies used in enhancing ECE teachers' practices through integration of technology in teaching, planning and children's learning. The study aimed at making contributions to research in early childhood education, focusing on integration of digital technology in teachers' professional practice, planning and documentation of children's learning.

\section{Theoretical Framework}

The study was grounded in social cultural perspective on knowledge and learning, Dewey (1997), social constructivism perspective, Vygotsky, (1998) and socialization distribution perspective, Dysthe, (1997). Social cultural oriented perspectives view construction of knowledge as essentially social and embedded in a community, while Vygotsky's (1998) view focuses mainly on the role of language in learning process. Consequently, Dysthe, (1976) views knowledge and learning as situated, distributed, mediated and depended on learning and participation in communities. As consequence of these perspectives, digital technology is the paradigm for introducing information technology in ECE teaching and learning environments. Since children in ECE have grown up in diverse social settings from previous generations, mainly through saturation of digital technology, it is essential to search ECE teachers' grounding in use of technology. If teachers were using technology in a range of activities for example computer games and soft ware for writing and drawing then adequate accessibility is inevitable.

In pursuit of implementing digital technology in teaching and learning environments, teachers require access to a variety of resource such as: Mobile technology, Computers, Digital cameras, Printers as well as Photocopiers. In addition, theoretical perspectives on curriculum concern should be taken into consideration given the importance of transforming pedagogies from traditional view to modern view. In this context, cultural, social, critical, selfdetermination, curriculum and pedagogical theories and practice should be implemented for success to be achieved in effective utilization of digital technology in facilitating teaching and learning.

\section{Conceptual Framework}

The study was founded upon Rageluth \& Garfinke, (1994) conceptual framework of system change. Understanding the process of change provides teachers in ECE with an insight on effective implementation of digital technology to cognitive, social, intellectual and knowledge construction to learners. Digital technology tools such as mobile phones, computers, digital cameras printers and photocopies when appropriately exploited benefit children's innate interest to actively create knowledge as well as recognize diverse challenging effects of technology. Given the range of technology tools accessed by children, sufficient access to by teachers in ECE whether in schools, laboratory, in homes or cyber should transform pedagogies from traditional view to modern view, therefore advancing knowledge about digital technology.

In consequence adequate change process based on digital technology empowers and develops critical awareness in teacher's analysis, value, assumptions, strengths and weaknesses in use of digital technology. When teachers create appropriate learning environments supported by developmentally appropriate technology learners are likely to experience enhanced learning, enriched engagement in technology, positive perception of technology as well as acquire skills and knowledge to use technology. 


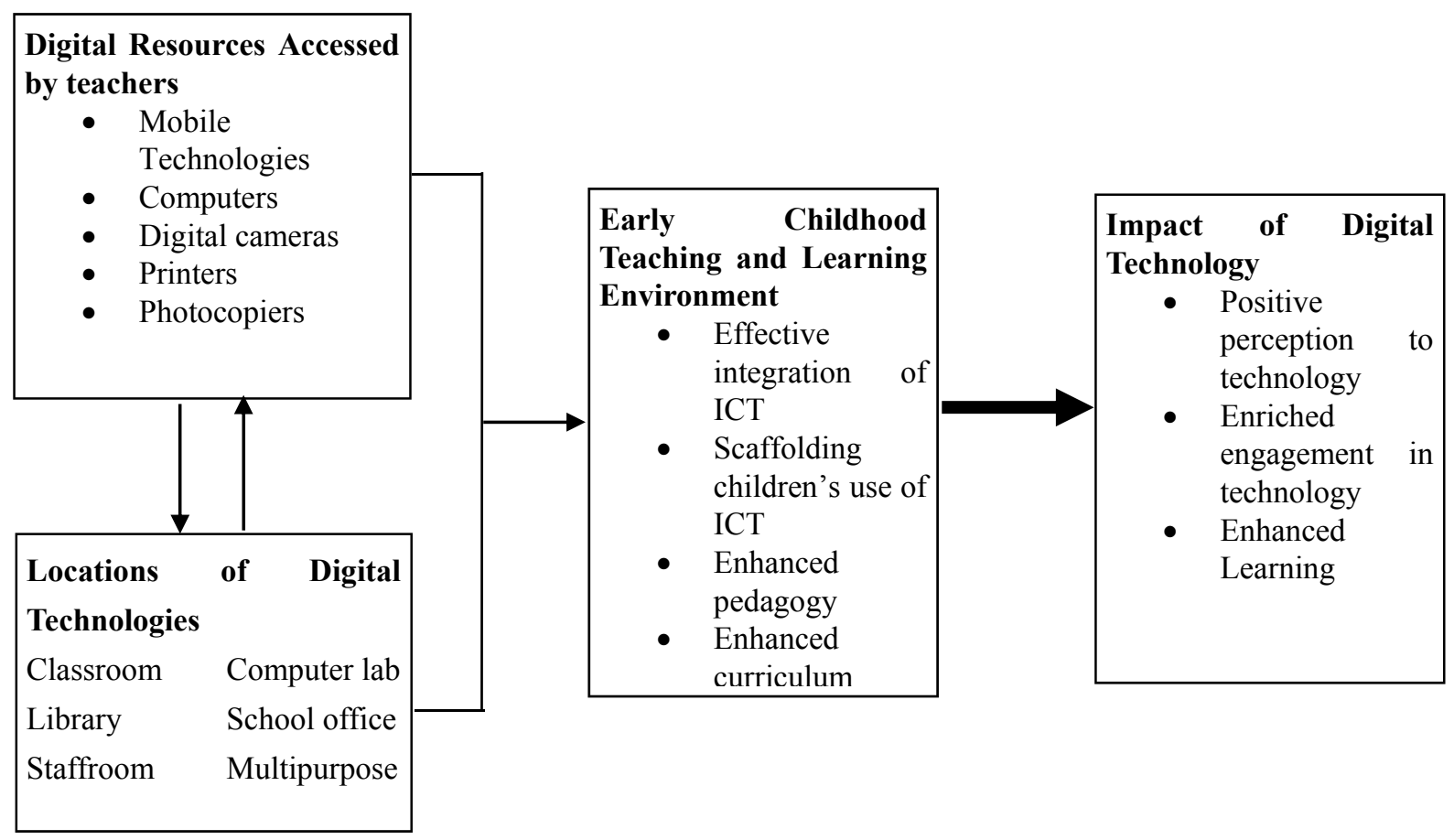

Figure 1. Conceptual Framework on adoption of digital technology in early childhood settings

\section{Data and Methodology}

This was a two-phase mixed methods study that embraced a combination of both qualitative and quantitative approaches. Phase One was implemented within two ECE settings with 11 teachers as participants $(\mathrm{N}=11)$. The teachers' $(\mathrm{N}=11)$ experiences on access to digital technologies in the two settings were identified through case study involving unstructured observations and semi-structured interviews. The main purpose of selecting two case study settings was to collect extensive and in-depth data (Baxter \& Jack, 2008; Leedy \& Ormrod, 2005; Oldridge, 2010; Rowley, 2002) on ECE teachers' access to digital technologies. Yin (2009) defines a case study as an empirical inquiry that investigates a contemporary phenomenon in depth and within its real-life context, especially when the boundaries between phenomenon and context are not clearly evident.

\subsection{Sampling Procedure}

Two ECE settings located in two education zones within Nairobi County, the capital city of Kenya were selected to participate in the study. The two settings were selected with the assistance of the Ministry of Education on the basis of one being high and the other being low in technology access. The criteria used in this selection included grouping ECE centers on the basis of the number of digital resources available at the settings. The ECE settings with over ten digital resources were classified as 'high technology,' whilst those with less than ten digital resources were grouped as 'low technology'. A combination of stratified and random sampling techniques (Teddlie \& Yu, 2007) was employed to select the two ECE settings representing high and low access to technology.

Table 1. Number of Teachers and Participants in Each Educational Zone

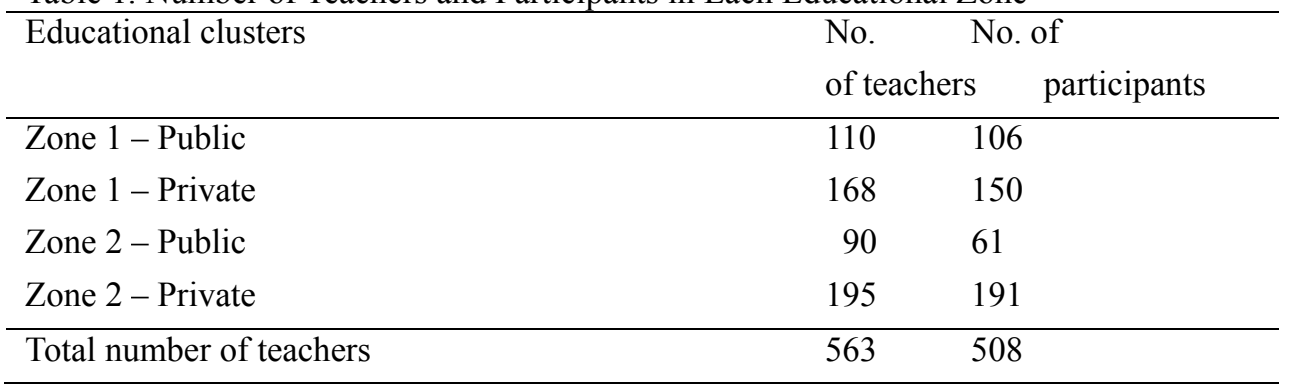




\subsection{Data Collection and Analysis}

Unstructured observations and interview schedules were used to collect data on access to digital technologies in the case study for phase one. Leedy and Ormrod (2005) advocates the use of unstructured observations in qualitative. Phase Two of this study employed use of questionnaires. Analysis of Phase One data informed the design of the survey questions used in Phase Two. This strategy was selected for the purpose of gathering data from a larger sample of ECE teachers in one district $(n=508)$. Overall, qualitative data obtained through semi-structured interviews were transcribed and coded. A Census and Survey Processing System (CSPro), databases were developed and used to enter all data provided by respondents in data files and Serpro for entering, tabulating, and disseminating data from censuses and other surveys (Iris Center University of Maryland, 2010).

\section{Study Findings}

\subsection{Availability and Access to Technology}

Data collected through field notes taken during observations and interviews with individual teachers at the commencement of phase one revealed non-availability and inadequate access to digital technologies by all participating teachers (n-11) in six classrooms across two settings of the study. Observation field notes also revealed that high technology setting was attached to a primary school that had a computer laboratory. During observations, none of the five participating teachers was seen accessing digital resources in the laboratory. Only one teacher (HTP3) reported having accessed computers in the school laboratory once every week of the school term. Additionally, majority of the teachers $(n=9)$ reported having access to personal mobile technologies as shown in table 2.

Table 2. Types of Digital Resources Accessed by Teachers

\begin{tabular}{lcc}
\hline \multicolumn{1}{c}{ Digital Resources } & High Tech Centre $(\mathrm{n}=5)$ & Low Tech Centre $(\mathrm{n}=6)$ \\
\hline Mobile technologies & 3 & 6 \\
Computers & 3 & 2 \\
Digital cameras & 0 & 1 \\
Printers & 1 & 0 \\
Photocopiers & 1 & 0 \\
\hline
\end{tabular}

Findings from table 2 disclosed five types of digital technologies accessed by case study teachers mostly outside their settings of practice. These comprised of mobile technologies, computers, digital cameras, printers and photocopiers. This data suggests that there was little difference between the two groups of teachers (high and low technology) in regard to types of digital technologies accessed. Mobile technologies were the most ubiquitous digital resource accessed. Moreover all the teachers at the low technology setting had access to mobile technologies yet two teachers at high technology centre did not have access to this innovation. One of these teachers explained the reason to lacking amobile phone as well as having no access to digital resources................ don't have a mobile because it got lost (was stolen), my co-teacher communicates with parents on my behalf. I am confined to my classroom and only take children to the computer lab and back to the class. (HTP4)

Further findings revealed that computers were accessed by three teachers in high technology setting and two in the low technology setting. One teacher at the high technology setting (HTP3) reported having accessed computes at her place of work. Two teachers (HTP5 and LTP3) in both settings reported having accessed computers at home and the additional two teachers accessed computers at a friend's house (HTP1 and LTP6). This data shows that only one teacher (HTP3) out of the entire study sample ( $\mathrm{n}=11)$ accessed computers at her centre of practice.

More data showed that 4 teachers (HTP1 HTP2, HTP4 and HTP5) in high technology centre did not have direct or daily access to computers at ECE centre despite its location in a primary school that had a computer laboratory. More still 2 teachers accessed family computers (HTP5) and also form a cyber (HTP1), external to their place of employment. Additionally, 2 teachers at the high technology centre (HTP2 and HTP4) had no access to computers even at home. During interviews, the HTP4 for instance simply stated.............. hardly use computers at school as well as home; you know this work is difficult. Therefore when I take my class to the computer lab, I get time to mark childrens' books. 
This finding shows that neither the HTP4 nor HTP5 provided explanation as to why they did not access computers in the school laboratory. A response provided by one teacher at high technology centre (HTP3) indicated having accessed computers in the school laboratory in addition to assisting children in computer lessons. Responses to interviews pointed out that, printers, photocopiers and digital cameras were accessed by only two teachers (HTP1 and LTP1) across two centers. High technology participant (HTP1) accessed both a printer and a photocopier elsewhere and not at the centre of practice. At low technology participant one (LTP1) had access to a digital camera at home. However, access to these resources was external to the ECE centers. More data revealed that, 2 teachers (LTP3 and LTP6) at low technology centre accessed computers at home. This data suggests that teachers have other means of accessing digital resources despite inadequate availability at the centers they are employed.

\subsubsection{The Study Examined Technology Resources Accessed by Teachers At Home and in ECE Settings.}

Findings are shown in Table 3.

Table 3. Technology Resources Accessed by Teachers at Home and in ECE Settings ( $\mathrm{N}=508)$

\begin{tabular}{lllllllcrc}
\hline ECDE Clusters & \multicolumn{2}{l}{ Zone One } & \multicolumn{2}{l}{ Zone One } & \multicolumn{2}{l}{ Zone Two } & \multicolumn{2}{l}{ Zone Two } \\
\hline & \multicolumn{2}{l}{ Public .n=106 } & private=150 & \multicolumn{2}{l}{ Public. N=61 } & \multicolumn{2}{l}{ Private. N=191 } \\
\hline Digital Technologies Accessed & Home & ECE & Home & ECE & Home & ECE & Home & ECE \\
\hline Computers & 48 & 46 & 87 & 88 & 41 & 46 & 86 & 90 \\
\hline Digital Cameras & 28 & 06 & 56 & 44 & 40 & 06 & 80 & 46 \\
\hline Digital Video Records & 03 & 04 & 17 & 16 & 08 & 04 & 23 & 12 \\
\hline Mobile Telephones & 105 & 104 & 147 & 144 & 59 & 57 & 187 & 175 \\
\hline Document Scanners & 01 & 01 & 05 & 17 & 05 & 01 & 09 & 17 \\
\hline Printers & 07 & 11 & 32 & 50 & 14 & 11 & 09 & 45 \\
\hline Photocopiers & 20 & 28 & 38 & 62 & 30 & 28 & 42 & 85 \\
\hline
\end{tabular}

Table 3 shows that teachers across the study district $(n=508)$ accessed seven types of digital technologies both at home and at ECE settings, including computers, digital cameras, digital video recorders, and mobile telephones; document scanners, printers and photocopiers. This data differs slightly from the case study data in which participating teachers in the two settings involved in Phase One had indicated having accessed five types of digital technologies mostly at home, at a friend's house, cyber but not in ECE settings. This finding indicates that the case study teachers from Phase One accessed all the digital technologies accessed by the survey teachers except digital video recorders and document scanners.

Further findings revealed that majority of the ECE teachers across the study district had access to mobile telephones both at home (98.03\%) and at ECE settings (94.49\%). These data indicates that mobile telephones were the most all-pervading type of digital technology accessed by ECE teachers across the district. A similar pattern was noted in the case study in which mobile telephones were the most ubiquitous digital technology accessed by majority of the teachers $(n=9)$ in the two settings. However, it was not clear from data provided by both case study and survey teachers whether mobile telephones were availed in ECE settings or were personally owned.

Additional findings showed that computers were the second most common type of digital technology accessed by teachers within the study district. Over $50 \%$ of teachers accessed computers at home. Similarly, $53.15 \%$ of teachers $(\mathrm{n}=508)$ accessed computers at their respective ECE settings. More data showed that less than $50 \%(\mathrm{n}=$ 204) of the survey teachers across the study district had access to digital cameras at home. Further, 102 teachers surveyed (20.08\%) also accessed digital cameras at their ECE settings. In the case study in Phase One, only one teacher in both settings had access to a digital camera at home. This finding suggests that majority of the ECE teachers across the study district have limited access to digital cameras both at home and at their ECE settings.

Further analysis showed that digital video recorders, document scanners, printers and photocopiers were accessed by very few teachers across the study district. There were 51 teachers across the whole district $(10.04 \%)$ accessing to digital video recorders at home; only 36 teachers $(7.09 \%)$ had access to the same 
technologies at ECE settings. More still, document scanners were the least accessed digital resource by teachers across the district: $3.94 \%$ at home and $7.09 \%$ at the ECE settings. Additionally, less than $25 \%$ of the teachers accessed printers both at home and at ECE settings. Less than30\% accessed photocopiers at home yet over 30\% accessed the same type of technologies at their ECE settings.

A similar trend was noted with the case study participants as none of the teachers in the two settings accessed digital video recorders, document scanners, printers and photocopiers either at home or atECE settings. The only case study teacher (HTP1) with access to printers and photocopiers accessed through cyber and not at home or her setting of practice. Data presented in this section suggests that ECE teachers in study district had inadequate access to varied digital technologies both at home and at ECE settings for professional practice. Inadequate access to varied digital technologies at ECE settings is likely to impact negatively on teachers' efforts of using technology in teaching, planning and documenting children's learning experiences.

\subsection{Availability and Access to Technology Resources in ECE Classrooms}

In order to determine accessibility to technology in classrooms, teachers were required to describe location of technology resources in ECE centers. Data in table 4 suggests that majority of digital technologies were located in school offices and not integrated in the teaching and learning environments. In regards to the case study, computers in high technology setting were located in computer laboratory and not in ECE classrooms. This suggests that teachers across the study district had limited access to technology resources in their classrooms.

Table 4. Locations of Digital Technologies in ECE Settings $(\mathrm{N}=508)$

\begin{tabular}{cccccc}
\hline & \multicolumn{5}{c}{ Educational clusters } \\
\hline & Zone One & & Zone Two \\
\hline Public & Private & Public & Private & Total \\
\hline Classroom & $f$ & $f$ & $f$ & $f$ & 05 \\
\hline Computer lab & 01 & 00 & 02 & 02 & 02 \\
\hline Library & 06 & 29 & 02 & 25 & 254 \\
\hline School office & 00 & 02 & 01 & 04 & 113 \\
\hline Staffroom & 41 & 80 & 20 & 03 & 02 \\
\hline Multipurpose & 06 & 01 & 02 & 00 & 07 \\
\hline room & 00 & 02 & & 00 \\
\hline
\end{tabular}

From findings in table 4, Zone One teachers identified having access to a larger number of digital technology resources overall $(\mathrm{n}=230)$ than those working in Zone Two settings. This data however does not show the type of or number of resources each teacher accessed at ECE settings.

This study sought to find out whether there were any significant differences among various groups of teachers in regard to access to technology resources. Each participating teacher was required to select up to five technology resources from each of the lists on home and ECE access. This means that the number of technology resources selected by each participating teacher ranged between 0 and 5 for home access and a similar range for ECE access. The value of ' 0 ' was used where a teacher did not make any selection as a way of showing inadequate access.

\subsection{Differences in Access across the Two Education Zones}

Independent two-sample t-test analyses were performed to determine whether there were any significant differences between teachers in both education zones in regard to selection of technology resources accessed at home (Table 4) and at their ECE settings (Table 5). 
Table 5. Independent T-Test Analysis for Teachers' Selection of Technology Resources Accessed at Home Based On Zones

\begin{tabular}{ccccccc}
\multicolumn{7}{c}{$\mathrm{N}=508$} \\
\hline Variable & $\mathrm{N}$ & Mean & $\mathrm{SD}$ & $\mathrm{df}$ & $\mathrm{t}$ & $\mathrm{p}$ \\
\hline Zone One & 256 & 2.29 & 1.34 & 501 & 0.31 & 0.753 \\
\hline Zone Two & 252 & 2.25 & 1.45 & 501 & 0.31 & 0.753 \\
\hline
\end{tabular}

According to the findings presented in Table 5, the means for the total aggregates of technology resources selected by teachers in Zone One and Zone Two were 2.29 and 2.25 respectively. This suggest that there was no significant difference between teachers in the two zones in relation to selection of technology resources accessed at home $[\mathrm{t}(501)=0.31, \mathrm{p}>.05]$. The data also suggests that both groups of teachers were more likely to be having equal levels of access in regards to technology resources accessed at home. This is surprising since the study had anticipated that teachers in Zone One had better access to technology resources at home than their counterparts in Zone Two. This assumption had been made based on the fact that teachers in Zone One worked in a middle class area where the community had relatively appropriate access to technology resources yet the reverse was true for Zone Two.

\subsection{Differences in Access Based on the Teachers' Gender}

Independent two-sample t-test analyses were performed to determine whether there were significant gender based differences in regards to teachers' selection of technology resources accessed at home as well as at the ECE settings. Results of the analysis are presented in table 6.

Table 6. Independent T-Test Analysis for Teachers' Selection of Technology Resources Accessed at Home Based on Gender $(\mathrm{N}=508)$

\begin{tabular}{ccccccc}
\hline Variable & $\mathrm{N}$ & Mean & $\mathrm{SD}$ & $\mathrm{df}$ & $\mathrm{t}$ & $\mathrm{p}$ \\
\hline Females & 445 & 2.24 & 1.39 & 79 & -1.13 & 0.261 \\
\hline Males & 63 & 2.46 & 1.43 & 79 & -1.13 & 0.261 \\
\hline
\end{tabular}

According to data in table 6, mean scores for ECE female and male teachers on the selection of technology resources accessed at home were 2.24 and 2.46 respectively. This indicates that there was no significant difference between female and male teachers in regards to the selection of technology resources accessed at home $[\mathrm{t}(79)=-1.13, \mathrm{p}>.05]$.

\section{Conclusions}

This study found that teachers in ECE across the entire County of study had limited access to digital technologies in teaching and learning environments due to non-availability. Despite non-availability of digital technologies in teaching and learning environments, majority of teachers accessed digital technologies at home, 'elsewhere', computer laboratory, library, school office, staffroom and multipurpose room. It needs to be noted that four teachers at the high technology setting did not access digital technologies in the computer laboratory that was located in a primary school attached to ECE centre of practice.

Further, this study found no significant differences between teachers in the two zones in relation to selection of digital technologies accessed at home and ECE settings; selection of digital technologies accessed at home and ECE settings between male and female teachers. However, the study found a significant difference between teachers in public and private settings (in favour of those in private settings) in regard to selection of digital technologies accessed at home and ECE settings.

If ECE teachers, both pre-service and in-service are to enhance professional daily practice, then exposure and use of varied digital technologies is essential. Teachers can enhance children's learning through access and use of diverse digital technologies in daily practice including planning and documentation of children' work. In view of this, more research work is needed to determine factors contributing to non-availability of varied developmentally appropriate digital technologies in ECE teaching and learning environments and especially in non-Western countries. 


\section{Recommendations}

The study makes the following recommendations:

- Teachers should enrich learning environment by developing appropriate literature on digital technology in ECE through emphasizing developmentally appropriate theories about children's learning, development, cognitive behaviours and emotional development.

- Teachers should integrate digital technology with aspects of the curriculum. If learning is to take place, meaningful content for real purposes, including features in children's play is crucial.

- Teachers should support children from diverse cultural backgrounds through appropriate software that engages in self -exploration and tailor the software to individual needs and cultural setting.

- Institutions should support teachers' training needs and assist in organizing appropriate professional development courses that support digital technology.

- Guidance should be provided to schools and teachers with special needs so that needs of learners may be matched more appropriately with the digital technology available.

- Emphasis should be on the application of digital technology in teaching and learning in teachers training at pre- service induction and continuity professional development in order to foster a culture of digital technology in school. More importantly digital technology should be integrated fully in the teaching and learning of content and curricular exercise.

- Schools and teachers should regularly review the use of digital technology to ensure greater integration within teaching and learning activities in class and other setting.

- Teachers should exploit potential of digital technology in developing a wide range of learning skills including problems- solving synthesis analysis and evaluation in order to enrich learning.

\section{References}

Ahmed, A., Clark-Jeavons, A., \& Oldknow, A. (2004). How can teaching aids improve the quality of mathematics education? Education Studies in Mathematics, 56(2/3), 313-328. https://doi.org/10.1023/B:EDUC.0000040412.39121.e0

Alberta Learning. (2004). Learning and technology policy framework. Retrieved September 20, 2004, from http://www.learning.gov.ab.ca/reading/policy/techframework/LTfwrk.pdf

Australian Communications and Media Authority. (2009). Use of Electronic Media and Communications: Early Childhood to Teenage Years: Findings from Growing Up in Australia: The Longitudinal Study of Australian Children ( 3 to 4 and 7 to 8-year-olds) and Media and Communications in Australian Families (8 to 17-year-olds), 2007.ACMA, Canberra.

Banas, J. R. (2010). Teachers' attitudes toward technology: Considerations for designing pre-service and practicing teacher instruction. Community \& Junior College Libraries, 16(2), 114-127. https://doi.org/10.1080/02763911003707552

Baxter, P., \& Jack, S. (2008). Qualitative case study methodology: Study design and implementation. The Qualitative Report, 13(4), 544-559.

Bayhan, P., Olgun, P., \& Yelland, N.J. (2002). A Study of Pre-school Teachers' Thoughts about Computer-assisted Instruction. Contemporary Issues in Early Childhood, 3(2), 298-303. https://doi.org/10.2304/ciec.2002.3.2.11

Cherney, I. D., \& Dempsey, J. (2010). Young children's classification, stereotyping and play behaviour for gender neutral and ambiguous toys. Educational Psychology, 30, 651-669. https://doi.org/10.1080/01443410.2010.498416

Christmann, E. P., \& Badgett, J. L. (2003). A meta-analytic comparison of the effects of computer-assisted instruction on elementary students' academic achievement. Information Technology in Childhood Education Annual, 2003(1), 91-104.

Dewey, J. (1997). Democracy and education. New York, Free.

Dysthe, O. (1996). The multi-voiced classroom. Written Communication, 13(3), 385-425. https://doi.org/10.1177/0741088396013003004

Haudland, SW. (2000). Early childhood classrooms in the 21st century: Using computers to maximize learning. 
Young Children, 55(1), 12-18.

Highfield, K., \& Mulligan, J. (2007). The role of dynamic interactive technological tools in preschoolers' mathematical patterning. In J.Watson \& K. Beswick (Eds.), Proceedings of the $30^{\text {th }}$ Annual Conference of the Mathematics Education.

IRIS Center at the University of Maryland. (2010). User Guide: CSPro Data Entry and Analysis Soft Ware for Implementers of UsaiD Poverty Assessment Tools. United States Agency for International Development.

Jo Shan Fu. (2013). ICT in Education: A Critical Literature Review and Its Implications. International Journal of Education and Development using Information and Communication Technology (IJEDICT), 9(1), 112-125.

Leedy, P. D., \& Ormrod, J. E. (2005). Practical research: planning and design ( $8^{\text {th }}$ ed.). New Jersey: Pearson Education, Inc.

Mitchell, L., \& Cubey, P. (2003). Characteristics of professional development linked to enhanced pedagogy and children's learning in early childhood settings: Best evidence synthesis. Wellington: Ministry of Education.

Momanyi, L., Norby, R., \& Strand, S. (2006). The need for integration of technology in K-12 school settings in Kenya, Africa. Association for the Advancement of Computing in Education Journal, 14(2), 154-177.

Murata, N. M., \& Tan, C.A. (2009). Collaborative teaching of motor skills for preschoolers with development delays. Early Childhood Education Journal, 36, 483-489. https://doi.org/10.1007/s10643-007-0212-5

Nikolopoulou, K. (2014). ICT Integration in Preschool Classes: Examples of Practices in Greece. Creative Education, 5, 402-410. https://doi.org/10.4236/ce.2014.56050

Nikolopoulou, K., Gialamas, V., \& Batsouta, M. (2010). Young children's access to and use of ICT at home. Review of Science, Mathematics and ICT Education, 4(1), 25-40.

O'Hara, M. (2008). Young children, learning and ICT: a case study in the UK maintained sector. Technology, Pedagogy and Education, 17(1), 29-40. https://doi.org/10.1080/14759390701847443

Oldridge, L. A. (2010). Digital foundations: A study of perceptions and practices surrounding the use of ICT in ECE centres. Doctor of Philosophy Thesis, Massey University, New Zealand.

Plowman, L., McPake, J., \& Stephen, C. (2008). Just picking it up? Young children learning with technology at home. Cambridge Journal of Education, 38(3), 303-319. https://doi.org/10.1080/03057640802287564

Plowman, L., McPake, J., \& Stephen, C. (2010). The technologisation of childhood? Young children and technology in the home. Children and Society, 24(1), 63-74. https://doi.org/10.1111/j.1099-0860.2008.00180.x

Plowman, L., Stevenson, O., Stephen, C., \& McPake, J. (2012). Preschool children's learning with technology at home. Computers \& Education, 59(1), 30-37. https://doi.org/10.1016/j.compedu.2011.11.014

Pohio, L. (2009). The implementation and integration of information and communication technologies in early childhood education: Teachers' perspectives. Unpublished Thesis. UNITEC Institute of Technology, Waitakere.

Rasanen, P., Salminen, J., Wilson, A. J., Aunio, P., \& Dehaene, S. (2009). Computer-assisted intervention for children with low numeracy skills. Cognitive Development, 24, 450-472. https://doi.org/10.1016/j.cogdev.2009.09.003

Republic of Kenya. (2012). Sessional Paper No. 14 of 2012, a policy framework for education and training: Reforming education and training in Kenya. Nairobi: Government Printer.

Roberts-Holmes, G. (2013). Playful and creative ICT pedagogical framing: a nursery school case study. Early Child Development and Care.

Rowley, J. (2002). Using case studies in research. Management Research News, 25(1), 16-27. https://doi.org/10.1108/01409170210782990

Teddlie, C., \& Yu, F. (2007). Mixed methods sampling: A typology with examples. Journal of Mixed Methods Research, 1, 77-100. https://doi.org/10.1177/2345678906292430

UNESCO. (2010). Recognizing the Potential of ICT in Early Childhood-Educational Analytical Survey. UNESCO Institute for Information Technologies in Education, Moscow.

Vygotsky, L. S. (1978). Mind in society. Harvard University Press.

Yelland, N. J. (2010). New technologies, playful experiences, and multimodal learning. Paper presented at the 
Annual Meeting of American Educational Research Association: Understanding Complex Ecologies in a Changing World, Denver, CO.

Yin, R. K. (2009). Case study research: Design and methods (4thed.). Applied Social Research Methods Series Vol. 5. New Delhi: Sage Publications, Inc.

Zitter, I., \& Hoeve, A. (2011). Hybrid and well-designed: Two guiding perspectives on the road to learning environments in the 21st century. National Centre for Expertise in Vocational and Training, ECBO: Netherlands.

\section{Copyrights}

Copyright for this article is retained by the author(s), with first publication rights granted to the journal.

This is an open-access article distributed under the terms and conditions of the Creative Commons Attribution license (http://creativecommons.org/licenses/by/4.0/). 